\title{
Tintin and the Capgras syndrome
}

\author{
H. Förstl; R. Howard; O. Almeida; B. Beats; A. Burns and R. Levy, Professor of \\ Old Age Psychiatry, Section of Old Age Psychiatry, Institute of Psychiatry, \\ De Crespigny Park, London SE5 8AF
}

Only around 300 cases of the Capgras syndrome have been reported in the medical literature. We report a widely read but scientifically neglected case of a mad scientist who showed this misidentification syndrome with classical and potentially dangerous features. The current literature on the psychopathology and neuropsychology of the Capgras-syndrome is briefly reviewed and discussed in the light of this new case.

\section{The study}

The work of writers and artists has often given a detailed account of medical and particularly of psychiatric conditions before the medical profession showed interest in them. The problem of identity and identification has exerted a fascinating influence on art of all periods. In the Capgras syndrome the patient identifies, with delusional intensity, familiar individuals as imposters. 'L'illusion de Sosie', the first designation of the syndrome described by Capgras \& Reboul-Lachaux (1923), refers to the Plautus' classical play 'Amphytrion'. Dostoyevsky (1846) and Ganger (1874) - to mention only the most famous examples - gave dramatic accounts of this misidentification syndrome.

Often these topics lose their mystery and fascination once they are absorbed by scientific rationalism. Nevertheless we would like to draw the attention of the scientific public to an original description of a classical Capgras syndrome which was published in the Belgian lay-press in 1946, translated in 31 languages including English and reprinted around the world (Hergé, 1946), long before psychiatry renewed its interest in this intriguing psychopathological phenomenon.

\section{Case report}

Embarked on a mission to save the Earth from overheating, Tintin, Captain Haddock and the accompanying astronomer Professor Phostle are attacked by Philippulus, Phostle's former rather unsuccessful co-worker.

Fig. 1 shows Professor Phostle's attempt to console his agitated and obviously enraged disciple. Phostle tries to use common sense and emotional warmth (s. gesture and eyebrows), but to no avail.

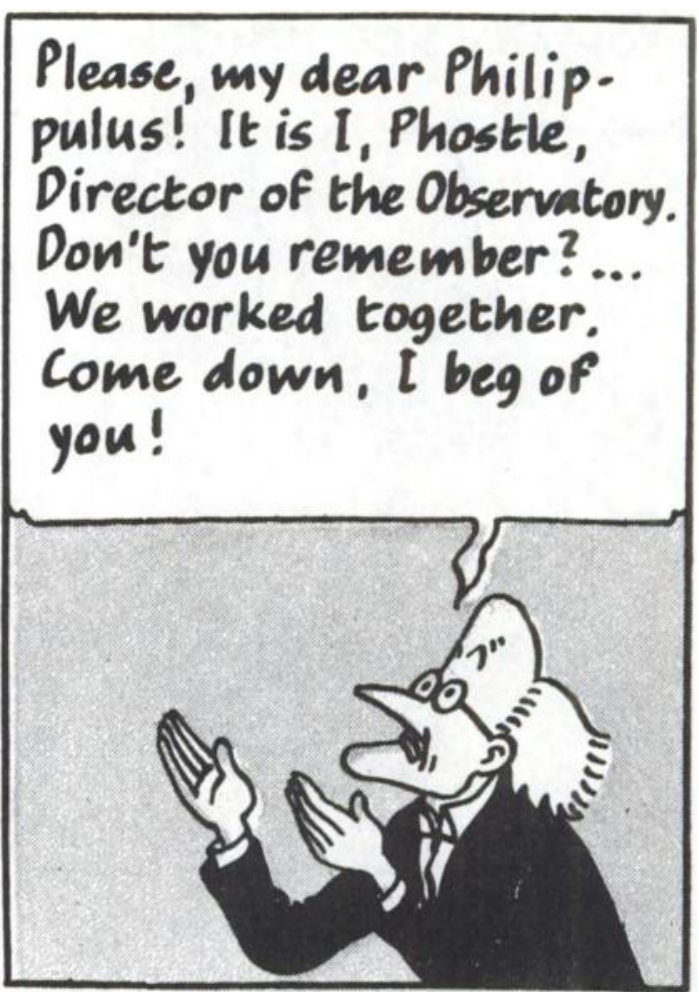

Fig. 1. Prof Phostle, the suspected imposter, in vain trying to identify himself.

Fig. 2 gives a clear outline of the patient and of his disturbance: he identifies the form of his former professor, but does not accept that he is that actual person. The patient holds this misconception with delusional conviction.

Fig. 3 demonstrates how Tintin successfully uses a psychotherapeutic transferential approach to tackling the patient's delusional system. Pretending to be his guardian angel, he immediately convinces Philippulus to obey and step down.

Fig. 4 shows two wardens-neatly dressed in moustache, uniform caps, white, long coats, tie and black trousers - taking care of the patient, who returns to be safely locked up in a mental hospital. 


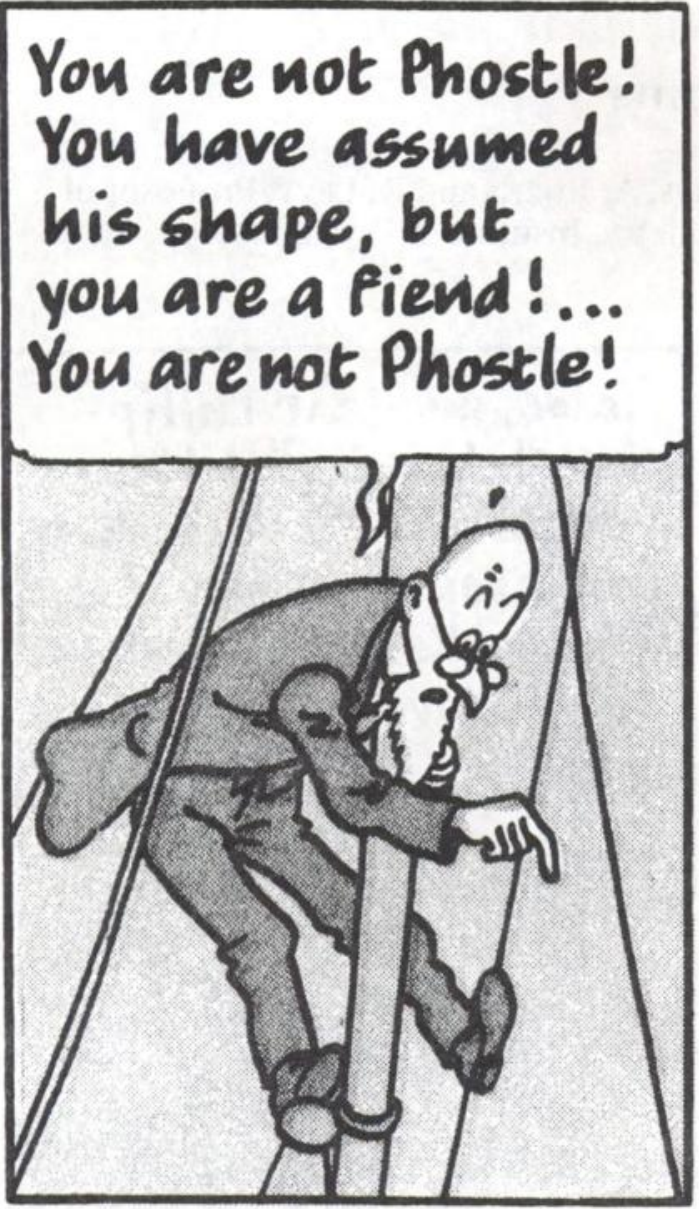

Fig. 2. Philippulus giving a most concise description.

\section{Comment}

Most practising doctors are acquainted with the exploits of the young journalist Tintin, who is accompanied by his lively Highland terrier Snowy and by the irritable alcoholic Captain Haddock. On their missions around the globe this team has encountered numerous strange characters, many of whom would seem to deserve psychiatric attention! From a scientific point of view, the episode presented above appears particularly noteworthy because it draws attention to the potential threat, pathogenic factors and therapeutic approach in a fascinating condition, the Capgras syndrome (1923).

The Capgras syndrome is characterised by the delusion that a person, usually with close emotional bonds to the patient, is replaced by a double, often a mischievous imposter (Capgras \& Reboul-Lachaux, 1923; Signer, 1987). This disturbance can be under-

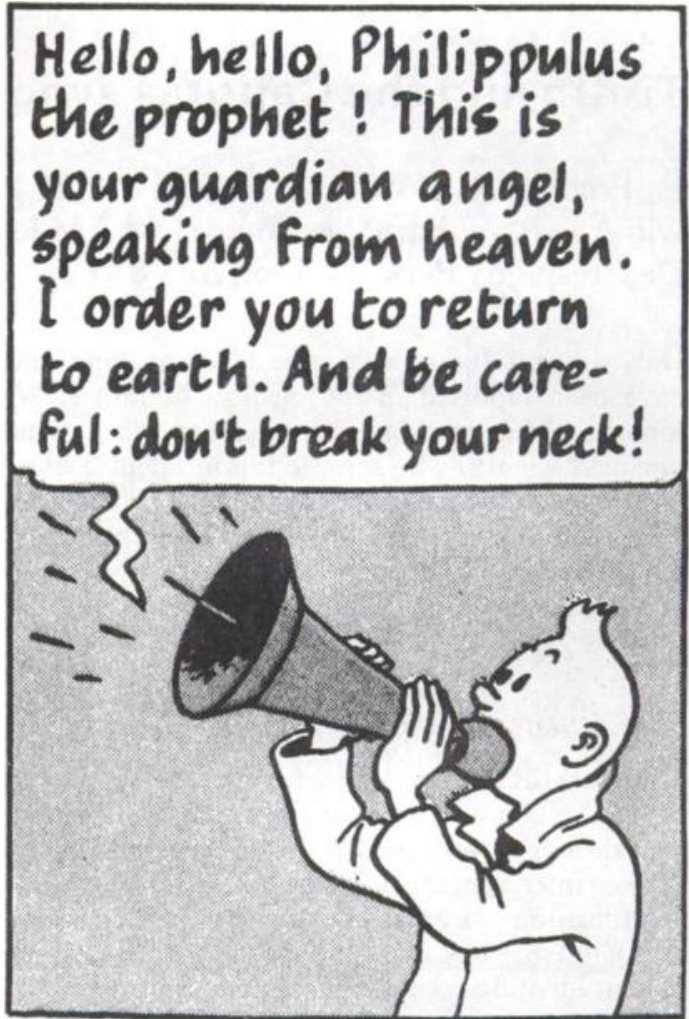

FIG. 3. Correct cunning psychotherapeutic approach.

stood as a form of "reduplicative paramnesia" (Pick, 1903). This is a complex memory disturbance in which patients retain a sense of familiarity but cannot integrate this into a certainty of identity (Alexander et al, 1979). This misidentification syndrome has been correctly considered to be a dangerous delusion, potentially leading to more violence than commoner and less complex psychoses (DePauw \& Szulecka, 1988).

This delusion can occur in the context of schizophrenia or affective disorder (Signer, 1987). However, a large number of patients clearly show signs of organic disease (Cummings, 1985), most commonly of either the right hemisphere or the frontal lobes (Alexander et al, 1979; s. Fig. 1).

We would suggest that in Philippulus' case life events have played a decisive part in his development of the Capgras syndrome (Foerstl, 1990). He is a hapless scientist, who we assume as he struggles for success and recognition, is chronically exposed to stress and frustration, resulting in burn-out. His conviction, expressed earlier in the story, that the earth would be destroyed in a collision with a shooting star was critical - tipping him over the edge into insanity and the mental hospital from where he has escaped. 


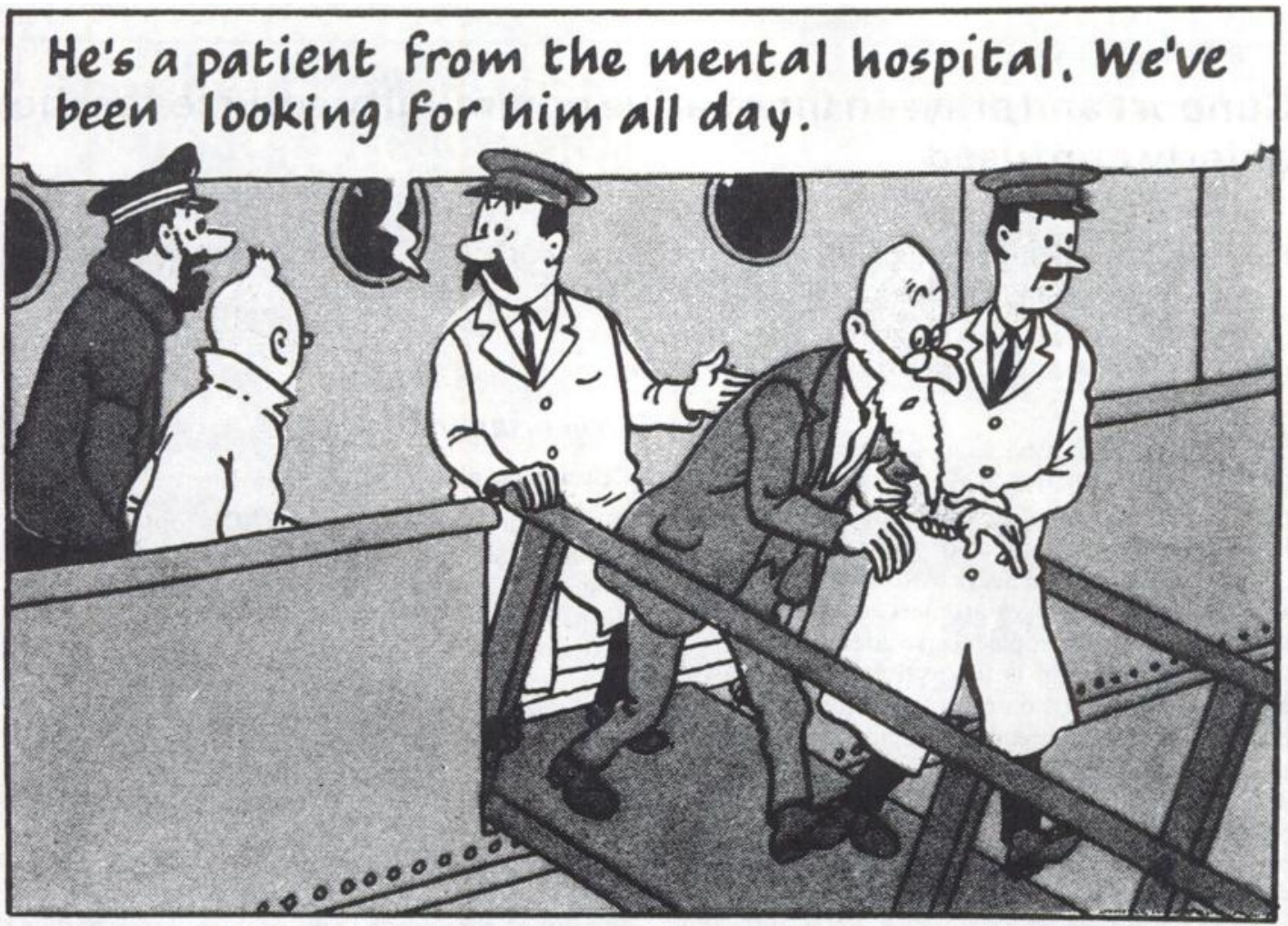

FIG. 4. Correct psychiatric male nursing.

\section{Acknowledgements}

We are grateful for permission to reproduce Figures 1 to 3 from The Shooting Star (artwork: Sundancer; publishers: Methuen Children's Books).

\section{References}

Alexander, M. P., Stuss, D.. T. \& Benson, D. F. (1979) Capgras syndrome; a reduplicative phenomenon. Neurology, 29, 334-339.

CAPGRAS, J. \& Reboul-Lachaux, J. (1923) L'illusion des "sosies" dans un delire systematise' chronique. Bulletin de la Societé de Medicine Mentale, 11, 6-16.

Cummings, J. L. (1985) Organic delusions; phenomenology, anatomical correlations, and review. British Journal of Psychiatry, 146, 184-197.
De Pauw, K. W. \& Szulecka, T. K. (1988) Dangerous delusions; violence and misidentification syndromes. British Journal of Psychiatry, 152, 91-96.

DostoyevsKy, F. M. (1846) Prikljucenija gospodina Goljadkina (The double). Dvojnik, Petersburgskaja poema.

FOERSTL, H. (1990) Capgras' delusion; an example of coalescent psychodynamic and organic features. Comprehensive Psychiatry, 31, 447-449.

GANGER, W. W. (1874) His life as myself. Journal Belge d'Experiences Etranges, 2, 2-4.

HergE , (1946) The Adventures of Tintin: the shooting star. Paris: Casterman.

PICK, A. (1903) Clinical studies III; on reduplicative paramnesia. Brain, 26, 260-267.

SigneR, S. F. (1987) Capgras syndrome: the delusion of substitution. Journal of Clinical Psychiatry, 48, 147-150. 